\title{
Socioeconomic status of emergency department users in Ontario, 2003 to 2009
}

\author{
April P. Tozer, MD*; Paul Belanger, $\mathrm{PhD}^{\dagger \ddagger}$; Kieran Moore, MD, MPH ${ }^{\ddagger}$; Jaelyn Caudle, MD, EMDM*
}

\section{ABSTRACT}

Objective: Emergency department (ED) overcrowding in Canada is an ongoing problem resulting in prolonged wait times, service declines, increased patient suffering, and adverse patient outcomes. We explored the relationship between socioeconomic status (SES) and ED use in Canada's universal health care system to improve our understanding of the nature of ED users to both improve health care to the most deprived populations and reduce ED patient input.

Methods: This retrospective study took information from the National Ambulatory Care Reporting System (NACRS) database for all ED visits in Ontario between April 1, 2003, and March 31, 2010. As there is no direct measure of SES available from ED visit records, a proxy measure of SES was used, namely a deprivation index (DI) developed from material and social factors from the 2006 Canadian census using the patient's residential neighbourhood. DI scores were assigned to ED visit records using Statistics Canada's Postal Code Conversion File, which links postal and census geography.

Results: A total of $36,765,189$ visits occurred during the study period. A cross-province trend was found wherein the most deprived population used EDs disproportionately more than the least deprived population (relative risk: $1.97195 \%$ confidence interval 1.969-1.973, $p<0.0001$ ). This trend was stable across the entire study period, although the divergence is attenuating.

Conclusion: Social determinants of health clearly impact ED use patterns. People of the lowest SES use ED services disproportionately more than other socioeconomic groups. Focused health system planning and policy development directed at optimizing health services for the lowest SES populations are essential to changing ED use patterns and may be one method of decreasing ED overcrowding.

\section{RÉSUMÉ}

Objectif: L'encombrement des services des urgences (SU) au Canada est un problème chronique, qui a pour effets de prolonger les délais d'attente, de diminuer la qualité des services, d'accroître les souffrances des patients et d'altérer l'évolution de leur état de santé. Nous avons donc examiné la relation entre le statut socioéconomique (SSE) des usagers et I'utilisation des SU dans le cadre du système de soins de santé universels au Canada afin de dégager les caractéristiques de ces usagers, et ce, dans l'optique d'améliorer la qualité des soins donnés aux populations les plus défavorisées et de diminuer le nombre de patients dans les SU.

Méthode: II s'agit d'une étude rétrospective dans laquelle les renseignements sur toutes les consultations faites dans les SU, en Ontario, entre le $1^{\mathrm{er}}$ avril 2003 et le 31 mars 2010, ont été tirés de la base de données National Ambulatory Care Reporting System (NACRS). Comme aucune mesure directe du SSE n'est inscrite dans les dossiers des malades qui vont consulter aux SU, nous avons utilisé une mesure de substitution du SSE, soit l'indice de défavorisation (ID) élaboré à partir de facteurs matériels et sociaux, tirés du recensement canadien de 2006, en nous référant aux quartiers résidentiels des malades. II y a eu attribution de cotes d'ID aux malades qui ont consulté aux SU, à I'aide du Fichier de conversion des codes postaux de Statistique Canada; celui-ci permet d'établir des liens entre les codes postaux et la situation géographique des lieux inscrits dans le recensement.

Résultats: Au total, 36765189 consultations ont été dénombrées durant la période à l'étude. Une tendance générale s'est dégagée de tous les SU de la province: les populations les plus défavorisées ont eu recours aux SU de manière disproportionnée par rapport aux populations les moins défavorisées (risque relatif: 1.971; intervalle de confiance à 95\%: 1.969-1.973; $p<0.0001$ ). La tendance $\mathrm{s}^{\prime}$ est révélée stable tout le long de la période à l'étude, bien que l'écart soit en voie de diminution maintenant.

Conclusions: Les déterminants sociaux de la santé ont une nette incidence sur le recours aux SU. Les personnes ayant le SSE le plus faible utilisent les SU de manière disproportionnée comparativement aux autres groupes socioéconomiques. Les changements d'habitudes quant à I'utilisation des SU passent par la planification d'un système de soins de santé adapté et l'élaboration de politiques visant l'optimisation des

From the Departments of *Emergency Medicine and †Geography, Queen’s University, and ¥Kingston, Frontenac, Lennox \& Addington Public Health, Kingston, ON.

Correspondence to: Dr. April P. Tozer, Department of Emergency Medicine, Kingston General Hospital, Empire 3, 76 Stuart Street, Kingston, ON K7L 2V7; matozer@sympatico.ca.

This article has been peer reviewed. 
services de santé dans les populations ayant le SSE le plus faible; peut-être serait-ce là aussi un moyen de diminuer I'encombrement des SU.
Keywords: emergency department crowding, emergency department use, emergency department wait times, social determinants of health, socioeconomic status
Emergency department (ED) overcrowding is a complex system-wide problem with multiple causes and no simple solutions ${ }^{1,2}$ In Canada, overcrowding of EDs is an ongoing problem resulting in prolonged wait times, service declines, increased patient suffering, and adverse patient outcomes. ${ }^{2}$ It is an issue that the Canadian government has made a priority to target. ${ }^{3-5}$ An important component of this problem is patient input into EDs. ${ }^{1}$ ED wait time initiatives have mainly focused on increased productivity and throughput in the ED. ${ }^{6,7}$ Evidence suggests that interventions designed to increase primary care accessibility are also effective in reducing ED input. ${ }^{8}$ Low socioeconomic status (SES) is associated with poorer health and health outcomes, including increased ED use..$^{9-11}$

A recent systematic review of $\mathrm{ED}$ use patterns recommended investigating the social determinants of health, such as SES, to untangle the complex and dynamic factors affecting ED service demands. ${ }^{12}$ Khan and colleagues examined low-acuity ED use from a health survey, Ontario Health Insurance Plan (OHIP) use, and National Ambulatory Care Reporting System (NACRS) data for an Ontario-based population sample. ${ }^{13}$ SES was defined broadly on high school completion and income. Low SES was found to be associated with increased ED use, regardless of visit urgency.

The objective of this study was to explore the association between SES and all ED visits in Ontario for the years 2003 to 2010 using a rigorous proxy of SES developed by Pampalon and colleagues. ${ }^{14-16}$ SES is defined by a deprivation index (DI) calculated from material and social factors derived from the 2006 national census: material deprivation measures access to goods and conveniences that are a part of modern life and social deprivation measures social cohesion and family, community, and/or workplace support. ${ }^{14-16}$ Geographic Information System (GIS) applications were then employed to spatially analyze the relationship between SES and ED use. We hypothesized that people of low SES use ED services disproportionately more than other socioeconomic groups, and geographically delineated areas of highest deprivation can be identified using these methods. These areas should be targeted for enhanced primary care and other health care resources to potentially reduce ED input from these areas. Evidence-based solutions aimed at reducing the flow of patients into EDs could be important for alleviating the problem of ED overcrowding in Canada and improving SES-related health disparities.

\section{METHODS}

\section{Study design}

This was a retrospective, observational, population-based study. The Queen's University Health Sciences and Affiliated Teaching Hospitals Research Ethics Board approved the study. A comprehensive extract of all ED visits in Ontario over 7 fiscal years was obtained from the NACRS database. These visits occurred between April 1, 2003, and March 31, 2010, and were geographically exhaustive across the province. Visit attributes mined from the database included the date and time of ED registration and the patient's postal code. A proxy SES was derived from the patient's residential neighbourhood using the DI for Ontario dissemination areas (postal code regions) developed by Pampalon and colleagues in $2009 .{ }^{16}$ Briefly, the DI is a compilation of six standard census variables thought to largely reflect an individual's socioeconomic condition. ${ }^{14-16}$ The material markers are education, employment, and income, whereas the social markers are marital status, living alone, and single-parent family status. The DI is measured at the dissemination area, which is the smallest geographic census area composed of approximately 400 to 700 people. ${ }^{16,17}$ Each census dissemination area has associated material, social, and combined DI scores calculated by Pampalon and colleagues. ${ }^{16}$ Using the patient's residential postal code, a DI score was ascribed to each ED visit via Statistics Canada's Postal Code Conversion File, which links postal and census geography. DI scores are divided into quintiles, with Q1 being the least deprived population and Q5 the most deprived population. ED users across Ontario during the study period were identified by location and level of deprivation.

\section{Data analysis and outcome measures}

The unit record of the NACRS database represents distinct visits by a single patient to a provincial ED. We appended to the data set the DI quintile rank 
(social, material, and combined) of the patient's residential postal code as a SES surrogate. Statistical analyses were conducted using the $\mathrm{R}$ Project for Statistical Computing. ${ }^{18}$ Our subsequent analyses focused on exploring cross-tabulations and relative risks of ED use, comparing Ontario's most deprived populations to Ontario's least deprived populations (Q5 to Q1). Our primary outcome measure was ED use in Ontario, both as a provincial total and by DI score quintile. We quantified $\mathrm{ED}$ use as raw visit counts and as proportions when subdivided by DI quintile. Our secondary outcome measure was the geospatial mapping of ED visits by DI score quintile.

\section{RESULTS}

A total of $36,765,189 \mathrm{ED}$ visits occurred during the study period. Figure 1 shows the tabulation of ED visits by combined material and social DI. The entire population of Ontario is divided into five DI quintiles (each $20 \%$ of the population). Theoretically, each quintile should have equal representation at the ED. As depicted in Figure 1, the Q1 population (least deprived) generated approximately 4.8 million ED visits during the study period, whereas the Q5 population (most deprived) generated approximately 9.5 million ED visits. The most deprived population (Q5) had almost double the number of ED visits compared to the least deprived population (Q1). In aggregate, a crossprovince trend exists wherein the most deprived population (Q5) used EDs disproportionately more than the least deprived population (Q1) (relative risk
[RR] 1.971, 95\% confidence interval [CT] 1.969-1.973, p $<0.0001)$. A similar pattern of ED use by DI quintile was maintained when material and social DI scores were examined separately (Figure 2 and Figure 3).

Our secondary outcome was to geospatially map ED visits by combined material and social DI score quintile. Figure 4 illustrates the "Golden Horseshoe" area of the province of Ontario, broken down by census dissemination area. This map includes the Greater Toronto Area, Hamilton, Niagara Falls, and the Niagara Peninsula. As one would expect, there are significant pockets of the most deprived population (Q5) within all census metropolitan areas.

\section{DISCUSSION}

This study assessed the relationship between determinants of health and ED use in Ontario. We found that people of low SES, as evidenced by low material, social, and combined DI scores, used ED services significantly more than other socioeconomic groups. The similar pattern of ED use found regardless of the type of DI score examined (material, social, or combined) highlights the stability of our findings. This trend remained stable over the entire study period. The Ontario government instituted multiple ED wait time initiatives during the time period encompassed by our study. The Pay-for-Results Program and the Process Improvement Program were started, respectively, in 2008 and 2009 as part of the government's "Emergency Room Wait Time Strategy," 19 yet yearly provincial ED use rates rose from 5.3 million ED visits in 2007 to 5.5 million in 2009.

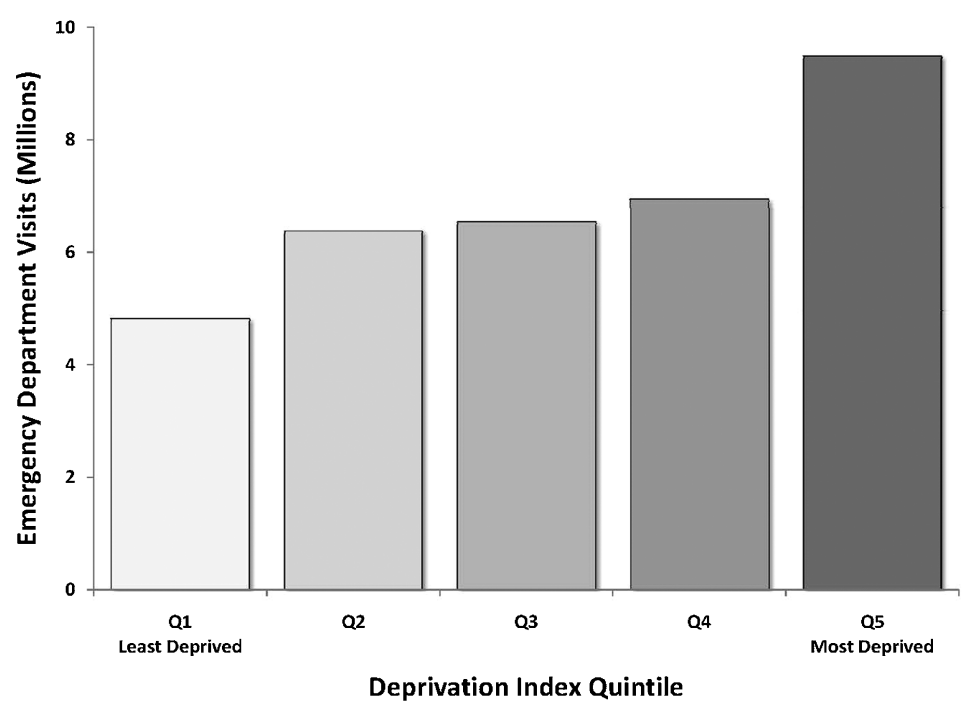

Figure 1. Emergency department visits by deprivation index (material and social combined). 


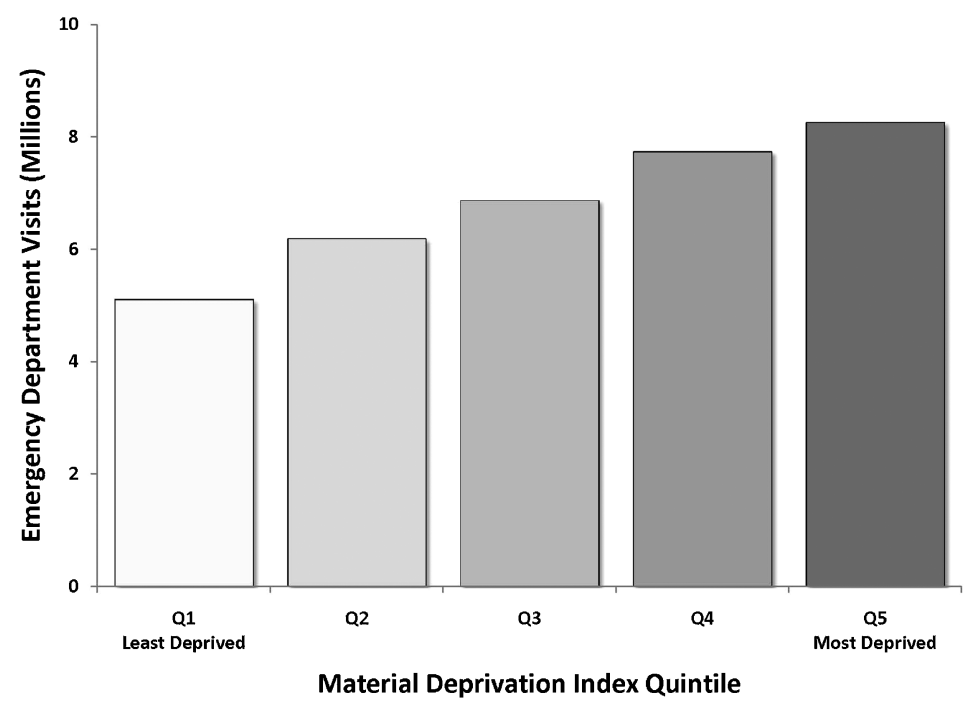

Figure 2. Emergency department visits by deprivation index (material).

Multiple studies in the United States have reported that high ED use rates exist in patients with poor health, low income, and a need for medical attention. Contrary to popular belief, these patients generally do not lack health insurance or a primary care physician. ${ }^{20-24}$ Several studies have even found that a change in health insurance status is related to increased $\mathrm{ED}$ use. ${ }^{20,25}$ With universal access to health care in Ontario, ED use should theoretically be equal throughout the population. As evidenced by our results, this is certainly not the case. This highlights the complex nature behind a patient's choice to seek medical care in an ED.

A notable study by Khan and colleagues also examined the association between SES and ED use in Ontario, finding that low SES was associated with increased ED use, regardless of visit urgency. ${ }^{13}$ This study did not meticulously define SES and had a limited population sample derived from a health survey over a brief time period. Our study is the first in Canada to look at ED use on a provincial basis using a rigorous definition of SES, producing results that build on and support the findings of the study by Khan and colleagues. ${ }^{13}$

To our knowledge, no previous studies have investigated the relationship between determinants of health and ED use using GIS technology. Having the ability to geographically locate regions of deprived populations that have high rates of ED use will enable targeted health care spending in these areas and a focus on improving access to primary health care. GIS technology can easily be applied to provincial NACRS data,

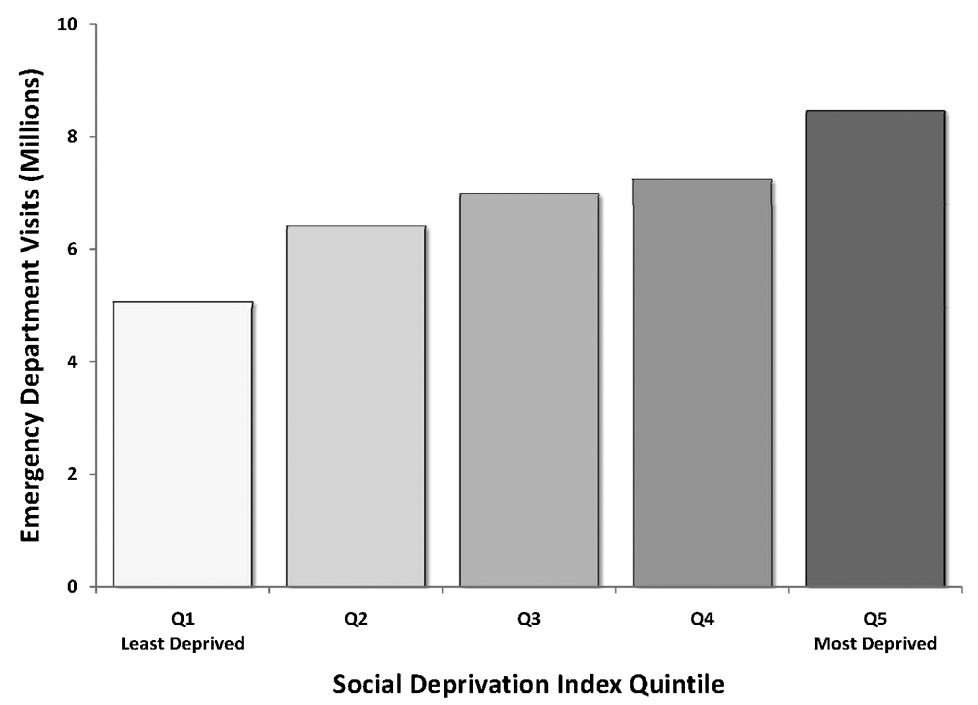

Figure 3. Emergency department visits by deprivation index (social). 


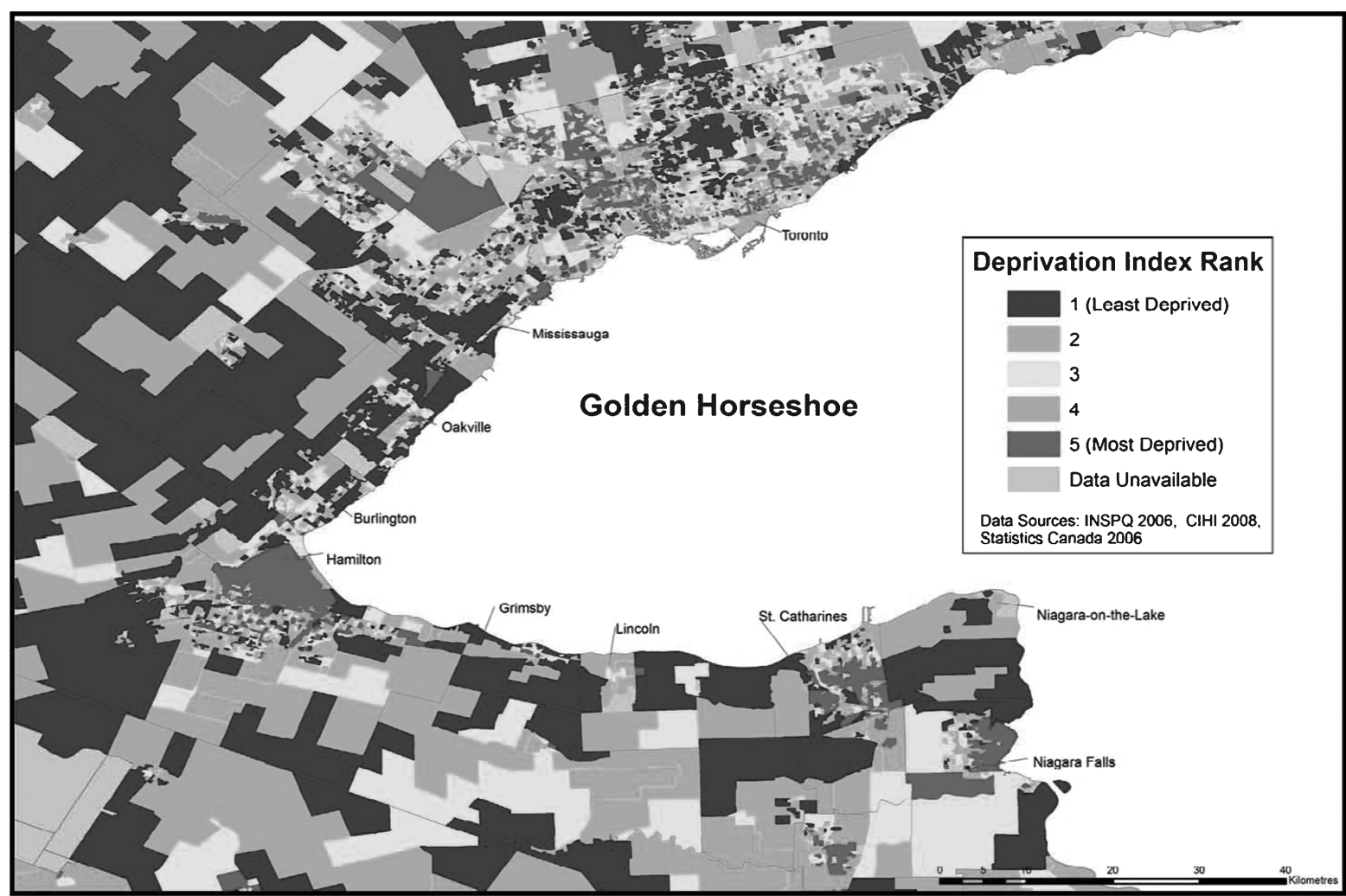

Figure 4. Combined material and social deprivation for the "Golden Horseshoe" by census dissemination area.

delineating health care use at the funding decision level (Local Health Integration Network), thereby allowing health policy development to be individualized to specific communities. For example, we have produced an invaluable geospatial representation of areas within the Golden Horseshoe region of Ontario that could benefit from enhanced health care resources, such as ambulatory services (see Figure 4). By examining an entire geographic area, health care resources can be placed logically where they reach the largest and most deprived population. The value of focused health care spending will be exponentially beneficial in our current cost-savings and results-driven health care environment.

\section{LIMITATIONS}

NACRS data were used to extract ED use information. Although the NACRS was not specifically designed for research purposes, coding errors from this database are not likely to be significant due to the large sample number.

The methods used to determine the DI are described in detail in Pampalon and colleagues ${ }^{15}$ and are subject to the limitations described therein, including those associated with applying a neighbourhood-level measure of SES to individuals. Specifically, a singular DI score was ascribed to the entire population within a particular dissemination area based on generalized census data from that geographic area. Complete uniformity of SES is unlikely, but with the analysis of over 36 million ED visits, any variance became insignificant. Other sources of variance, such as the significant association between age and education level, were standardized according to the age-sex structure of the Canadian population. ${ }^{15,16}$

The method by which DI scores were determined in this study relied on mapping the postal code from each ED visit to its corresponding census dissemination area. This was successful for $96.6 \%(35,508,116)$ of all ED visits. There was no reason to suspect spatial bias in the visits that could not be geolocated.

For the purposes of this study, we compared Q1 (the least deprived population) with Q5 (the most deprived population). Comparing these two extreme populations provided the most contrast regarding health outcomes, such as ED use, and helped to magnify health disparities in Canada that are present despite our access to universal health care.

\section{CONCLUSION}

Material and social determinants of health clearly impacted ED use patterns: people within the lowest 
SES used ED services more than other socioeconomic groups. This study provided a novel view of ED use, highlighting potential contributions to addressing ED overcrowding in Canada and leading to improved health for the most deprived population. Focused health system planning and policy development directed at optimizing health services for the lowest SES populations are essential to changing ED use patterns and decreasing ED wait times. In further studies, we will examine the relationship between determinants of health (by DI) and age, sex, Canadian Triage and Acuity Scale score, access to family physicians, and discharge diagnosis.

Competing interests: This study was supported by a Queen's University Research Initiation Grant.

\section{REFERENCES}

1. Canadian Agency for Drugs and Technologies in Health. CADTH assessment series on Canadian ED overcrowding - 2006. Emergency department overcrowding in Canada: what are the issues and what can be done? Overview. Available at: http://cadth. ca/en/products/health-technology-assessment/publication/ 621 (accessed August 20, 2012).

2. Caandain Association of Emergency Physicians. Position statement on emergency department overcrowding from the Canadian Association of Emergency Physicians, 2009. Available at: http://www.caep.ca (accessed August 20, 2012).

3. Tripartite Committee (OMA, OHA, MOHLTC) - 2006. Improving access to emergency care: addressing system issues. Available at: http://www.health.gov.on.ca/en/common/ministry/ publications/reports/improving_access/improving_access.pdf (accessed August 20, 2012).

4. Ministry of Health and Long-Term Care. Ontario wait times, emergency room wait times. 2008. Available at: http://www. health.gov.on.ca/en/pro/programs/waittimes/edrs/default.aspx (accessed August 20, 2012).

5. Ministry of Health and Long-Term Care. Ontario's Pay-forResults Program. 2010. Available at: http://health.gov.on. ca/en/news/release/2010/jul/bg_20100729_1.pdf (accessed August 20, 2012).

6. Canadian Agency for Drugs and Technologies in Health. $\mathrm{CADTH}$ assessment series on Canadian ED overcrowding 2006. Emergency department overcrowding in Canada: what are the issues and what can be done? Report \#4: Interventions to reduce overcrowding in emergency departments. Available at: http:// cadth.ca/en/products/health-technology-assessment/publication/ 621 (accessed August 20, 2012).

7. Ministry of Health and Long-Term Care, Ontario wait times, Ontario's emergency room wait time strategy. Available at: bttp:// www.health.gov.on.ca/en/pro/programs/waittimes/edrs/strategy.aspx (accessed August 20, 2012).

8. Flores-Mateo G, Violan-Fors C, Carrillo-Santisteve P, et al. Effectiveness of organizational interventions to reduce emergency department utilization: a systematic review. PLoS One 2012; 7:e35903, doi:10.1371/journal.pone.0035903.
9. Canadian Institute for Health Information. Reducing gaps in health: a focus on socio-economic status in urban Canada. 2008. Available at: https://secure.cihi.ca/free_products/Reducing Gaps_in_Health_Report_EN_081009.pdf (accessed August 20, 2012).

10. Stern RS, Weissman JS, Epstein AM. The emergency department as a pathway to admission for poor and high-cost patients. FAMA 1991;266:2238-43, doi:10.1001/jama.1991. 03470160070034.

11. Alter DA, Stukel T, Chong A, et al. Lesson from Canada's universal care: socially disadvantaged patients use more health services, still have poorer health. Health Aff 2011;30: 2274-83, doi:10.1377/hlthaff.2009.0669.

12. Lowthian JA, Curtis AJ, Cameron PA, et al. Systematic review of trends in emergency department attendances: an Australian perspective. Emerg Med 7 2011;28:373-7, doi:10.1136/emj.2010.099226.

13. Khan Y, Glazier RH, Moineddin R, et al. A populationbased study of the association between socioeconomic status and emergency department utilization in Ontario, Canada. Acad Emerg Med 2011;18:836-43, doi:10.1111/j.1553-2712. 2011.01127.x.

14. Pampalon R, Guy R. A deprivation index for health and welfare planning in Quebec. Chronic Dis Inj Can 2000;21:104-13.

15. Pampalon R, Hamel D, Gamache P. A comparison of individual and area-based socio-economic data for monitoring social inequalites in health. Health Rep 2009;20:85-94.

16. Pampalon R, Hamel D, Gamache $\mathrm{P}$, et al. A deprivation index for health planning in Canada. Chronic Dis Can 2009;29:178-91.

17. Statistics Canada. Dissemination area. Available at: http:// www12.statcan.gc.ca/census-recensement/2011/ref/dict/geo021eng.cfin (accessed August 20, 2012).

18. The R Project for Statistical Computing. Available at: http:// www.r-project.org (accessed August 20, 2012).

19. Ontario's emergency room wait time strategy. Available at: http:// news.ontario.ca/mohltc/en/2009/05/ontarios-emergency-roomwait-time-strategy-1.html (accessed August 20, 2012).

20. Zuckerman S, Shen YC. Characteristics of occasional and frequent emergency department users: do insurance coverage and access to care matter? Med Care 2004;42:176-82, doi:10.1097/01.mlr.0000108747.51198.41.

21. Weber EJ, Showstack JA, Hunt KA, et al. Does lack of a usual source of care or health insurance increase the likelihood of an emergency department visit? Results of a national population-based study. Ann Emerg Med 2005;45:412, doi:10.1016/j.annemergmed.2004.06.023.

22. Hunt KA, Weber EJ, Showstack JA, et al. Characteristics of frequent users of emergency departments. Ann Emerg Med 2006;48:1-8, doi:10.1016/j.annemergmed.2005.12.030.

23. Miller JB, Brauer E, Rao H, et al. The most frequent ED patients carry insurance and a significant burden of disease. Am 7 Emerg Med 2012 July 16. [Epub ahead of print]

24. Weber EJ, Showstack JA, Hunt KA, et al. Are the uninsured responsible for the increase in emergency department visits in the United States? Ann Emerg Med 2008;52:108-15, doi:10.1016/j.annemergmed.2008.01.327.

25. Ginde AA, Lowe RA, Wiler JL. Health insurance status change and emergency department use among US adults. Arch Intern Med 2012;172:642-7, doi:10.1001/archinternmed.2012.34. 